\title{
Determination Decision Support System Using The School Fees Spp Simple Additive Weighting (Saw)
}

\author{
Ika Puspita ${ }^{1}$, Arjon Samuel Sitio ${ }^{2}$ \\ ${ }^{1,2}$ Informatics Engineering Study Program, STMIK Pelita Nusantara, Jl. St. Iskandar Muda No. \\ 1 Medan, Nort Sumatera, Indonesia, 20154 \\ E-mail: ikap9308@gmail.com
}

\begin{abstract}
School tuition fees are very influential on an educational institution, without the cost of school tuition fees experiences how an education agency Difficulties for students who can not afford. In making decisions 1 to Determine the cost of school tuition, especially in educational institutions. In educational institutions need to be supported by how much the school tuition fees will be paid. Educational institutions still Determine tuition fees manually. From the above problems, a decision support system (DSS) was made using the Simple Additive weighting method. Based on the calculation using the Simpe Additive weighting method for school tuition fees, the Reviews largest value is $2: 55,2.55$ so that alternatives A3, A5 are the alternatives to be chosen as alternatives entitled to pay school fees. Namely Citra Dewi,112 067.
\end{abstract}

Keywords: SPP, SPK, SAW

\section{Introduction}

Technological developments can contribute to the revolution in various fields, including in educational institutions. Both in realizing the effectiveness and efficiency of work in improving services to the public. From the results obtained from the study is the determination of the cost of school tuition with Simple Additive weighting method (SAW) to determine how much students have to pay school tuition fees that students / i can go to school. To get the ranking that most or biggest to help a school to find a solution, predicts the number of school tuition fees paid by students / i Simple Additive weighting method (SAW) to get the result effectively and efficiently.

\section{Theory}

\subsection{Simple Additive Weighting (SAW)}

According to Diana, S.Si., M.Kom (2018: 60) explains metodeSimple Additive Weighting (SAW) is one method of multi-criteria decision making are simple and classic.

This method is included in the weighting method otherwise known as a weighted summation method. The basic concept is to find the SAW method dri weighted summation rating performance on each alternative on all attributes.

Diana (2018: 60), Completion steps in the method Simple Additive weightingare as follows :

a) Specify the criteria that will be used as a reference in the decision, namely $\mathrm{Ci}$.

b) The rating determines the suitability of each alternative on each criterion

c) Make decisions based on criteria matrix $(\mathrm{Ci})$, then normalized matrix based on equations that are tailored to the type attribute (attribute or attributes benefit costs) in order to obtain the normalized matrix R.

d) The final results obtained from the ranking process is the summation of the normalized $\mathrm{R}$ matrix multiplication with the weight vector in order to obtain the greatest value is selected as the best alternative (Ai) as a solution.

Xij : The value of each alternative are possessed of each criterion

n Many criteria

wj : Results of the initial weight normalized value

Formula for normalization are:

$$
r_{i j}=\frac{x_{i j}}{\operatorname{Max}_{i} x_{i j}} \text { jikajadalahatributkeuntungan benefit }
$$




$$
r_{i j}=\frac{\operatorname{Min}_{i} x_{i j}}{x_{i j}} j i k a j a d a l a h a t r i b u t b i a y a \cos t
$$

Preference value for each alternative (Vi) is given as:

$$
V_{i}={ }_{j=1}^{n} w_{j} r_{i j}
$$

\section{Research methods}

\subsection{Framework Research}

Research framework is one which is used for steps to resolve the problem in a study. This study discusses the "Decision Support Systems SPP Schools Costing Method Using Simple Additive Weighting (SAW)". As well as discuss how to model the implementation of the research will be used. Stages will be done by following the steps in accordance with the study design workflow.

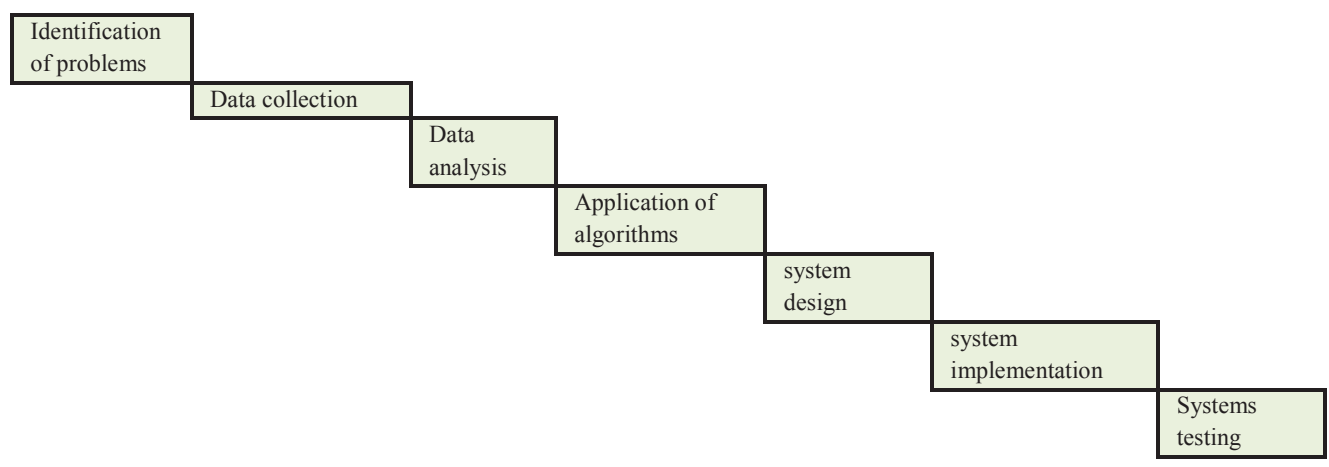

Figure 1. Framework Research

\subsection{Use Case Diagram}

Below is a model casediagram use decision support systems determining the cost of school fees:

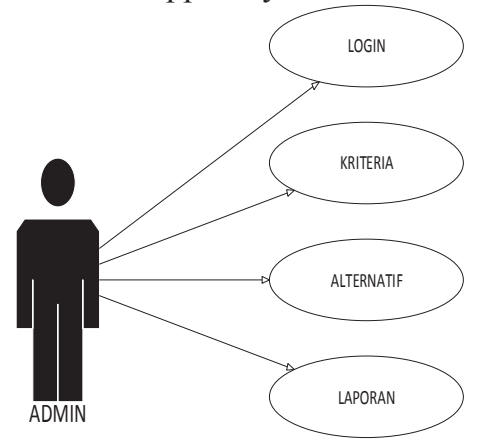

Figure 2. Use Case Diagram

\section{Results and Discussion}

Decision support systems costing SP determination schools using SAW method. Simple Additive weighting (SAW) is a process to assist in the decision making, the concepts used are looking for a weighted summation of rating performance on each alternative on all attributes,

The steps in the SAW method is as follows:

a) Specifies an alternative, namely $\mathrm{Ai}$.

b) Specify the criteria that will be used as reference in decision-making, ie $\mathrm{Cj}$.

c) Providing value every alternatifpada compatibility rating for each criterion.

d) Determining the weight of preference or importance level (W) of each criterion.

e) Creating tables suitability rating of each alternatifpada each criterion.

f) Make a decision matrix formed from a table rating the suitability of each alternative on each criterion.

g) Normalized decision matrix by calculating the value of ternomalisasi performance rating (rij) of the 
alternative Ai on criteria $\mathrm{Cj}$.

h) The results of the performance rating ternomalisasi value (rij) form a normalized matrix (R)

i) The final result of the preference value (Vi) obtained from the sum of the normalized rows of the matrix multiplication element (R) with a preference weighting (W) corresponding eleman column matrix (W). The calculation result $\mathrm{Vi}$ greater value indicates that the alternative $\mathrm{Ai}$ is the best alternative.

Table 1.

Data respective school tuition fees to the criterion

\begin{tabular}{ccccc}
\hline \multirow{2}{*}{$\begin{array}{c}\text { Alterna } \\
\text { tive }\end{array}$} & \multicolumn{4}{c}{ Criteria } \\
\cline { 2 - 5 } & C1 & C2 & C3 & C4 \\
\hline A1 & 0.80 & 0.60 & 0.60 & $0: 50$ \\
A2 & 0.80 & 0.80 & 0.80 & $1: 00$ \\
A3 & 0.60 & 0.80 & $1: 00$ & $1: 00$ \\
A4 & 0.80 & $0: 20$ & $1: 00$ & $0: 50$ \\
A5 & 0.60 & 0.80 & $1: 00$ & $1: 00$ \\
A6 & 0.60 & 0.80 & 0.80 & $1: 00$ \\
A7 & 0.80 & 0.60 & 0.80 & $0: 50$ \\
A8 & 0.80 & 0.60 & $1: 00$ & $1: 00$ \\
A9 & 0.80 & 0.60 & $1: 00$ & $1: 00$ \\
A10 & 0.80 & 0.80 & 0.80 & $0: 50$ \\
\hline
\end{tabular}

Information :

C1: Parents Work

C2: Income Parents

C3: Number of Dependents Parents

C4: Student Status

a. Determining the weights to each criterion

table 2.B

Oboth Criteria

\begin{tabular}{|l|c|c|c|c|}
\hline \multirow{2}{*}{} & \multicolumn{4}{|c|}{ Criteria } \\
\cline { 2 - 5 } & $\mathrm{C} 1$ & $\mathrm{C} 2$ & $\mathrm{C} 3$ & $\mathrm{C} 4$ \\
\hline $\begin{array}{l}\text { Weight } \\
\left(W_{j}\right)\end{array}$ & $0: 20$ & 0.60 & 0.80 & $1: 00$ \\
\hline
\end{tabular}

$$
\begin{gathered}
r_{i j}=\frac{x_{i j}}{\operatorname{Max}_{i} x_{i j}} \text { jikajadalahatributkeuntungan benefit } \\
r_{i j}=\frac{\operatorname{Min}_{i} x_{i j}}{x_{i j}} \text { jikajadalahatributbiaya cost }
\end{gathered}
$$

b. Parents' job

$$
\begin{aligned}
& r_{11}=\frac{0.80}{\max (0.80 ; 0.80 ; 0.60 ; 0.80 ; 0.60 ; 0.60 ; 0.80 ; 0.80 ; 0.80 ; 0.80)}=\frac{0.80}{0.80}=1 \\
& r_{12}=\frac{0.80}{\max (0.80 ; 0.80 ; 0.60 ; 0.80 ; 0.60 ; 0.60 ; 0.80 ; 0.80 ; 0.80 ; 0.80)}=\frac{0.80}{0.80}=1 \\
& r_{13}=\frac{0.60}{\max (0.80 ; 0.80 ; 0.60 ; 0.80 ; 0.60 ; 0.60 ; 0.80 ; 0.80 ; 0.80 ; 0.80)}=\frac{0.60}{0.80}=0.75
\end{aligned}
$$

c. income Parents

$r_{21}=\frac{0.60}{\max 0.60 ; 0.80 ; 0.80 ; 0.20 ; 0.80 ; 0.80 ; 0.60 ; 0.60 ; 0.60 ; 0.80}=\frac{0.60}{0.80}=0.75$ 